\title{
FOOD SCIENCE AND NUTRITION
}

\section{Application of colour parameters for assessing the quality of Arabica and Robusta green coffee}

\author{
Natalina Conceição Bicho, ${ }^{1,2}$, António Eduardo Leitão², José Cochicho Ramalho ${ }^{3}$ and \\ Fernando Cebola Lidon ${ }^{1 *}$ \\ ${ }^{1}$ Departmento de Ciências da Terra, Faculdade de Ciências e Tecnologia da Universidade Nova de Lisboa, \\ Campus da Caparica, 2829-516 Caparica, Portugal \\ ${ }^{2}$ Plant-Environment Interaction Group, Center of Environment Agriculture and Development, Tropical Research \\ Institute, I.P., Quinta do Marquês, Av. República, 2784-505 Oeiras, Portugal
}

\begin{abstract}
This work aims to achieve fast and non-destructive indicators that enable the definition of the quality of green coffee from Coffea arabica and $C$. canephora, respectively Arabica and Robusta, in high commercial samples (which displayed, respectively, medium sieve between 17.4 and 19.2, trade homogeneity of $94.3 \%$ and $97.0 \%$, mass of 1000 beans with values of $213.16 \mathrm{~g}$ and $151.36 \mathrm{~g}$, apparent densities of green coffee not significantly different, showing values of 0.629 and $0.630 \mathrm{~g} \mathrm{~cm}-3$ and moisture ranging between 9.056 and 9.243\%). Being these samples within the established range of the international market, and ensuring good storage conditions, the chromatic parameters $\mathrm{L}^{*}$ (lightness), $\mathrm{C}^{*}$ (chroma) and $\mathrm{H}^{\circ}$ (tone or hue angle) of these samples were assessed using illuminants D65 and C. It was concluded that through the application of colour parameters the quality of green coffee can be assessed. Yet, as coordinate a* (contribution of red or green) strongly affects tone of the green coffee, the illuminant type used in the measurement must be defined and/or combined in order to accurately characterize product quality.
\end{abstract}

Key words: Arabica coffee, Chromatic parameters, Robusta coffee, Technological quality

\section{Introduction}

The family Rubiaceae includes the Coffea genus that has at least103 species, with commercial relevance for C. arabica L., C. canephora Pierre ex Froehner, $C$. liberica Bull ex Hiern and $C$. dewevrei Wild and Durand cv. Excelsa, that represents, respectively Arabica, Robusta, Liberica and Excelsa types of coffee (Bicho et al., 2011c). C. arabica grows in $85 \%$ of coffee producing countries, predominantly in the American Continent, accounting for approximately $65-75 \%$ of the world coffee production, whereas $C$. canephora is predominantly cultivated in Asia and Africa (this continent with about $80 \%$ of total plantation), being responsible for about $25-35 \%$ of worldwide coffee yield. The other two species, $C$. liberica Bull ex. Hiern and $C$. dewevrei cv. Excelsa, are cultivated in Africa, accounting for

Received 08 July 2013; Revised 02 August 2013; Accepted 09 August 2013; Published Online 11 September 2013

*Corresponding Author

Fernando Cebola Lidon

Departmento de Ciências da Terra, Faculdade de Ciências e Tecnologia da Universidade Nova de Lisboa, Campus da Caparica, 2829-516 Caparica, Portugal

Email: fj1@fct.unl.pt about $1 \%$ of world production (Bicho et al., 2011c).

The world green coffee production has been growing since the sixties, with total production varying between $c a .4 .2$ and 7-8 million tonnes, between 1960 and the last decade (ICO, 2009). World consumption of green coffee stabilized at ca. 7 million tonnes per year, but only $25 \%$ are consumed in producing countries (Bicho, 2005). Also, the global green coffee consumption is not matching the increased production, provoking price depression. This could leads to a quality deterioration of the produced coffee, because the producers tend to limit the financial costs, with less investment in crop and harvest management (Bicho, 2005). Nevertheless, the recognized positive effects on human (Florián et al., 2013) health points to an increase of the trade market in the near future.

Coffee beans quality depends on moisture content, defects, bean size, some chemical compounds and preparation of a sample to perform cup tasting (Bicho et al., 2011b). To perform such physical quality analysis, standard methods are being used to characterize technological quality of green coffee, namely particle size, medium sieve, 
most frequent sieve, share split, cumulative calibration, trade homogeneity, mass of 1000 coffee beans, apparent densities, strange bodies and defects, mass losses on drying and olfactory and visual parameters. However, such physical analysis to characterize technological quality of green coffee should be fast and easy to perform, as well as accurate and with a low cost (Bicho et al., 2011a, 2012). Colour has been used for quality assessment of green coffee beans (Nelson, 2005; Bicho et al., 2012) and there have also been studies using image processing for grain quality inspection (Soedibyo et al., 2010). Also, previous studies of colour parameters underline its importance for roasting coffee degree assessment (Bicho, 2005; Bicho et al., 2012). In this scope, this work aims at to study the use of non-destructive chromatic parameters to help in quality evaluation of green coffee bean that might influence the sensory quality of the drink. For that, using the illuminants $\mathrm{D}_{65}$ and $\mathrm{C}$, were analysed two green coffees (Arabica from Brazil and Robusta from India, representative from the two main traded species), having commercial characteristics. The results will be related to grain physical characteristics, in order to determine if a chromatic analysis could constitute a fast, reliable and low cost method for green coffee quality evaluation.

\section{Materials and Methods}

Green beans from commercial lots of the two most representative traded species, Coffea arabica from Brazil and Coffea canephora from India, 4-6 months after yielded, were characterized in terms of its physical quality. The samples were supplied by NovaDelta company (Portugal).

Sampling of Coffea arabica and Coffea canephora was carried out according to ISO 4072 (1982), as recommended by the ICO for sampling green coffee in bags. The sampling process began with the selection of green coffee bags, at random (a minimum of $10 \%$ of the lot). The selected bags were separated from the lot and, with a probe, $30 \pm 6$ $\mathrm{g}$ of coffee were collected in triplicate from three different points in the bag (top, middle and bottom). After collection and standardization of the portions, these were mixed, for an overall take of green coffee, with a minimum mass of $1.5 \mathrm{~kg}$.

The particle size analysis followed ISO 4150 (1991). A sample of each coffee $(100.0 \pm 0.1 \mathrm{~g})$ was passed through a set of sieves with round holes. After mild shaking for three minutes, the fraction retained on each sieve (mesh 20 through 16) and in the receptacle was weighted (with an accuracy of $100 \mathrm{mg}$ ). Data are presented in mass percentage, and corresponds to the average of three trials. The medium sieve, the most frequent sieve, the share split, the cumulative calibration, and the trade homogeneity, were calculated according to Esteves and Oliveira (1970). The share split corresponds to the percentage of the bean mass retained on each sieve. The cumulative calibration expresses the cumulative percentage of the accumulated bean mass retained on each sieve. The medium sieve indicates the weighted average between the share split and the numbers of the sieves used for calibration. The most frequent sieve is the sieve that retained the highest percentage of coffee during the calibration test split. The trade homogeneity considers the maximum percentage of coffee retained in two consecutive sieve numbers, during the calibration test split (Esteves and Oliveira, 1970).

Following Instrução Normativa $N^{o} 8$ (2003), the levels of big, medium and small bean were also determined, considering the amounts retained in the sieves $19-17,16-15$ and 14 or smaller, respectively.

The mass of 1000 coffee beans was determined by extrapolation, after weighting 100 beans without defect, following Esteves and Oliveira (1970). Withdrew from the sample, after homogenization, 100 green coffee beans were weighed. Data are the average of five replicates per sample of green coffee.

The determination of apparent density followed NP 2285 (1991), using a container of known volume, with $10 \mathrm{mg}$. The difference between replicates did not exceed $2 \%$ of the average of five replicates.

Foreign bodies and defects were determined according to ISO 4149 (2005). Green coffee beans $(300.0 \pm 0.1 \mathrm{~g})$ were spread over an orange surface, being observed under diffuse natural light. The defective beans and foreign objects were split up into categories, as proposed by ISO 10470 (2004), being counted and weighed. For each category the number of units and the mass percentage was determined following ISO 10470 (2004). Considering that foreign bodies and defected beans do not have an equal contribution to the sensory profile of a coffee drink, different systems of counting defects, for marketing purposes, have been followed (ISO 10470, 2004; WP Board $\mathrm{N}^{\circ}$ $1005 / 06,2006)$. As a general pattern, the concept of defect, at a commercial level, was related with the presence of a number of units of each category of foreign or defective beans, allowing the equivalence of defects in accordance with the procedures mentioned above. Following these methods, for each type of defective beans, a score 
was assigned, according to tables of defects. The total score pointed the number of defects, for purposes of marketing coffee. This determination was based on the ICC resolution 420 (2004), being considered exportable Arabica or Robusta coffee if there were no more than 86 or 150 defects per 300 $\mathrm{g}$, respectively. In the case of LIFFE classification system (WP Board $\left.n^{\circ} 1005 / 06,2006\right)$, the defects in the Robusta coffee are analysed in $500 \mathrm{~g}$ samples.

The determination of mass losses of green coffee beans by drying, was based on ISO 6673 (2003) and ICC resolution $\mathrm{N}^{\circ} 420$ (2004). Ten grams of green coffee beans were placed in capsules (previously dried $1 \mathrm{~h}$ at $105 \pm 1{ }^{\circ} \mathrm{C}$, and subsequently allowed to cool down at room temperature in a desiccator) and dried for $16 \mathrm{~h} \pm 30$ $\min$ at $105 \pm 1{ }^{\circ} \mathrm{C}$. Data are the average of simultaneous experiments performed in triplicate.

The olfactory and visual assessment followed ISO 4149 (2005). This survey was completed by the analysis of the bean shape, according to Esteves and Oliveira (1970). For the olfactory test, the containers with the samples of green coffee were opened and inhaled, to detect strange or unpleasant smell, being the results recorded as "abnormal" or "normal".

For the visual examination of the beans, samples were spread on a smooth and orange surface, being examined under subdued or artificial light (NP 1795, 1989), in order to determine the: botanical origin of coffee; type of coffee, according to the preparation process, as indicated by NP 1535 (1977); uniformity and dominant colour. The latter was classified, according to NP 1795 (1989), in blue, green, white, yellow and brown. Visual assessment of the beans shape considered the criterion of Esteves and Oliveira (1970).

A Minolta colorimeter CR-300 was used to green coffee colour assessment on beans and grinded coffee, using $\mathrm{D}_{65}$ and $\mathrm{C}$ illuminants. White tile, used as standard, with the coordinates: $\mathrm{Y}=93.10, \mathrm{x}=0.3161, \mathrm{y}=0.3326$ or $\mathrm{L}^{*}=97.27, \mathrm{a}^{*}=$ $0.01, b^{*}=1.98$, for the illuminant $D_{65} ; Y=93.10$, $\mathrm{x}=0.3136, \mathrm{y}=0.3197$ or $\mathrm{L}^{*}=97.26, \mathrm{a}^{*}=+0.01, \mathrm{~b}^{*}=$ 1.94 , for the illuminant $\mathrm{C}$. The colorimeter was first calibrated to white Yxy coordinates, specific of each. Then, the colour space was chosen to obtain the results expressed in the chromaticity coordinates $L^{*} a^{*} b^{*}$ samples, for the selected illuminant. According to McGuire (1992), the coordinate $\mathrm{L}^{*}$ represents the lightness (contribution of black or white, varying between 0 and 100); $a^{*}$ indicates the contribution of red or green (when its the value is positive or negative, respectively); $b^{*}$ the contribution of blue or yellow (when its value is negative or positive, respectively). The coordinate $\mathrm{L}^{*}$ is perpendicular to the plane containing the chromaticity coordinates $\mathrm{a}^{*}$ and $\mathrm{b}^{*}$ (McGuire, 1992). Considering the coordinates $\mathrm{L}^{*} \mathrm{a}^{*} \mathrm{~b}^{*}$, the colour is expressed through $\mathrm{L}^{*} \mathrm{C}^{*} \mathrm{H}^{\mathrm{o}}$, being: $\mathrm{L}^{*}$ the lightness; $\mathrm{C}^{*}$ the chroma or saturation (Chervin et al., 1996); $\mathrm{H}^{\mathrm{o}}$ the tone (or hue angle, which indicates colour variation in the plane formed by the coordinates $a^{*}$ and $b^{*}$ ) (Chervin et al., 1996). These parameters were determined considering (McGuire, 1992; Chervin et al., 1996): $\mathrm{C}^{*}=\left(\mathrm{a}^{2}+\mathrm{b}^{2}\right)^{1 / 2} ; \mathrm{H}^{\mathrm{o}}=(\operatorname{arctg}(\mathrm{b} / \mathrm{a}) / 6.2832) \times 360$ (if a $>0$ and $\mathrm{b} \geq 0)$, or $\mathrm{H}^{\mathrm{o}}=180+(\operatorname{arctg}(\mathrm{b} / \mathrm{a}) / 6.2832) \mathrm{x}$ 360 (if $\mathrm{a}<0$ and $\mathrm{b} \geq 0$ or $\mathrm{b}<0$ ), or $\mathrm{H}^{\mathrm{o}}=360+(\operatorname{arctg}(\mathrm{b} / \mathrm{a}) / 6.2832) \times 360$ (if $\mathrm{a}>0$ and $\mathrm{b}<$ $0)$. The overall colour difference, $\Delta \mathrm{E}$, was determined using the equation $\Delta \mathrm{E}=\left[(\Delta \mathrm{L})^{2}+(\Delta \mathrm{a})^{2}+(\Delta \mathrm{b})^{2}\right]^{1 / 2}$ (Chervin et al., 1996).

\section{Statistical Analysis}

Data were statistically analysed using one-way ANOVA ( $\mathrm{P} \leq 0.05)$ applied to the studied parameters. Based on the ANOVA results, a Tukey's test was performed for mean comparison, for a $95 \%$ confidence level. Different letters indicate significant differences in a multiple range analysis for $95 \%$ confidence level.

\section{Results and Discussion}

The particle size of coffee Arabica and Robusta, according to the fractional calibration showed that the most frequent sieve, was number 17 and 19 for Arabica and Robusta coffee seeds, respectively (Figure 1). The result obtained for Arabica green coffee is in agreement with previous works (Bicho, 2005; Bicho et al., 2012). The medium sieve remained between 17.4 and 19.2 for Arabica and Robusta coffees, respectively, thus, according to Instrução Normativa $\mathrm{N}^{\circ} 8$ (2003) the samples had big beans but the trade homogeneity was lower in Arabica coffee (94.3\%), relatively to Robusta coffee (97.0\%).

The cumulative percentage of green Arabica and Robusta coffee accumulated until the $17^{\text {th }}$ sieve was $100 \%$ and $99.8 \%$, respectively. Considering that the bean size, coffee samples were found commercially homogeneous, since they offer a level of coffee held in two successive screens larger than 90\% (Esteves and Oliveira, 1970). This commercial characteristic resulted of an undergoing calibration stage during the benefit prior to marketing (implicating the separation of 
green coffee beans, by the shape and size, using a set of sieves with perforation of variable shape and size), being the homogeneity of the coffee beans, of particular importance for roasting, to avoid the burning of smaller grains (Cortez, 2001; Bicho et al., 2012).
The mass of 1000 beans of green Robusta coffee was significantly higher relatively to coffee Arabica, with values of $213.16 \mathrm{~g}$ and $151.36 \mathrm{~g}$, respectively (Table 1). The data was similar to that reported by Coste (1992) for Arabica coffee, but according to Fazuoli (1986) slightly higher for the Robusta coffee.

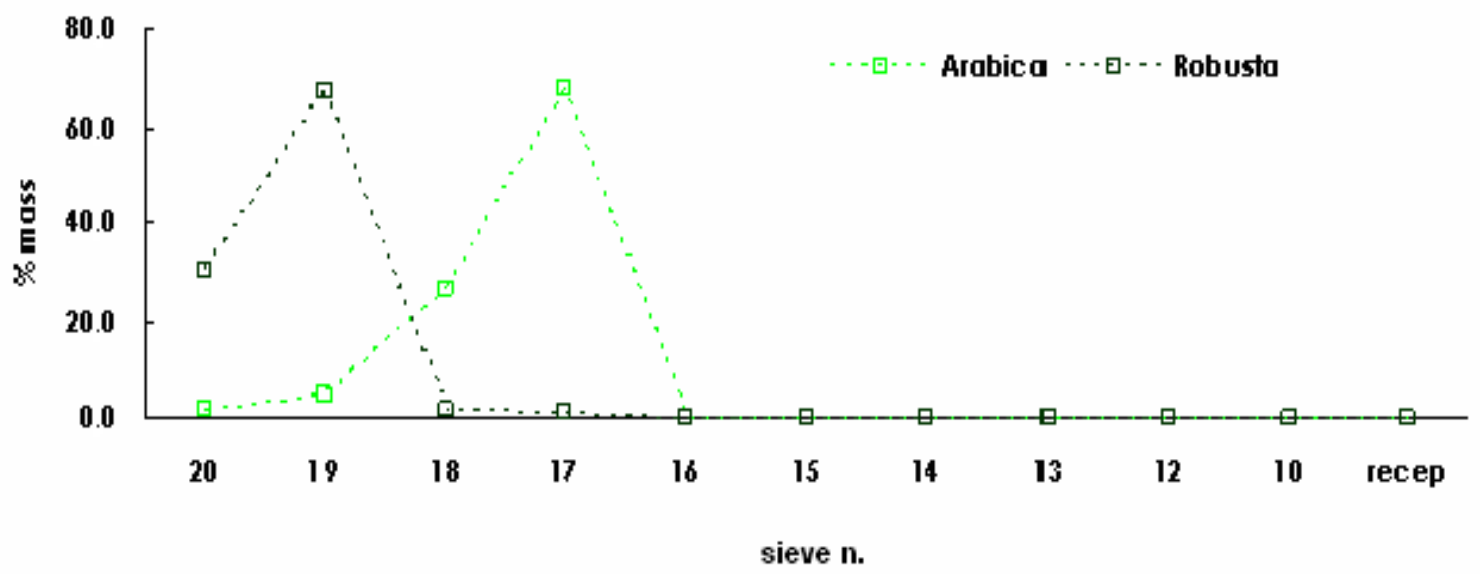

Figure 1. Fractional calibration of Arabica and Robusta green coffee beans.

Table 1. Physical characterization of Arabica and Robusta coffees. For the mass of 1000 beans and apparent densities, each value is the mean \pm S.E. Different letters $(r, s)$ indicate significant differences, in a multiple range analysis, for $95 \%$ confidence level. NA means "Not Applicable". The analysis of defects considered the systems: Brazil/Nybot (one defect in Arabica coffee equals 3 units of shell bean); Vietnam (one defect of Arabica and Robusta coffee as a coefficient of 0.20); LIFFE (one unit of Robusta coffee equals a defect); ISO-10470 ( 0 and 0.5 coefficient was applied over the mass percentage of the defect, to determine mass loss and the sensorial impact, respectively).

\begin{tabular}{llll}
\hline & & Arabica coffee & Robusta coffee \\
\hline $\begin{array}{l}\text { Mass of 1000 coffee beans }(\mathrm{g}) \\
\text { Apparent density }\left(\mathrm{g} \mathrm{cm}^{-3}\right)\end{array}$ & & $151.36+0.47^{\mathrm{r}}$ & $213.16+1.40^{\mathrm{s}}$ \\
Defects & & $0.629 \pm 0.004^{\mathrm{r}}$ & $0.630 \pm 0.004^{\mathrm{r}}$ \\
& Name & Shell bean & Shell bean \\
& Number of units & 44 & 17 \\
& Mass (\%) & 0.01 & 0.01 \\
& Brazil/Nybot criterion & 14.6 & $\mathrm{NA}$ \\
& Vietnam criterion & 4.8 & 3.4 \\
& LIFFE criterion & NA & 28.3 \\
& ISO 10470 - Mass losses & 0 & 0 \\
& ISO 10470 - Sensorial & 0.01 & 0.01 \\
Mass loss on drying & & $9.06 \pm 0.03^{\mathrm{r}}$ & $9.24 \pm 0.03^{\mathrm{r}}$ \\
Processing type & & & Normal \\
Olfactory assessment & & Normal & \\
Visual assessment & Colour & yellowish & yellowish \\
& Uniformity & uniform & uniform \\
\hline
\end{tabular}


Moreover, the apparent densities of green coffee Arabica and Robusta were not significantly different, showing values of 0.629 and $0.630 \mathrm{~g} \mathrm{~cm}^{-3}$, respectively (Table 1), but there is a clear difference between the apparent density of Arabica and Robusta coffees, for similar moisture contents. Defects associated with foreign matter to the coffee, or with matters unrelated to the beans from the fruit, were not found in the surveyed coffee, which was a further indication of quality ISO 10470 (2004). Defects associated with irregular beans also could not be detected. Only small quantities of shell beans were found (Table 1). Accordingly, these data further indicated that green Arabica coffee could be exported, with the International Coffee Organization certificate of origin (ICC resolution $\mathrm{n}^{\circ} 420,2004$ ) and additionally could be reported as a coffee "gourmet", according to the classification of ABIC (2007). Considering the defects found, Robusta green coffee could also be exported with the International Coffee Organization certificate of origin, being additionally accepted by LIFFE as green coffee classified with the quality of type I, because had less than 150 defects per $500 \mathrm{~g}$ of coffee, thus, presenting a commercial value without financial penalty.

The moisture content of green coffee beans ranged between 9.056 and $9.243 \%$, (Table 1), being therefore within the established range of the international market, and ensuring good storage conditions. Indeed, the moisture content in marketable green coffee bean should not exceed $12.5 \%$ according to the technical regulation of identity and quality for classification of the benefited raw green coffee bean (Instrução Normativa $\left.\mathrm{N}^{\mathrm{o}} 8,2003\right)$. Otherwise the beans will be easily attacked by fungi, allowing the accumulation of ochratoxin A to prohibited levels (in Europe, according to the Regulação (CE) $\mathrm{N}^{\circ}$ 123, 2005, higher than $5 \mathrm{mg} \mathrm{kg}$ ) and other mycotoxins, undergoing as well a marked colour change (Coste, 1992). Through the prevention of mould development the quality of green coffee is favoured, since its occurrence might produce an undesirable odour and give an unpleasant flavour to the drink, which leads to rejection of these beans for roasting and marketing (Instrução Normativa $\mathrm{N}^{\circ} 8,2003$ ).

Considering that the absence of any odour in green coffee is considered an additional indicator of quality coffees, during the primary processing, storage or transportation, it is further desirable to minimize the proximity of coffee to be dried or dehydrated, to the peel and pulp or fertilizers, since these materials can develop particularly unpleasant odours (Coste, 1992). Indeed, the odours coming from chemical contamination or other sources persist even after roasting and in the produced drink (Coste, 1992), so they depreciate coffee commercial value (Instrução Normativa $\mathrm{N}^{\circ} 8$, 2003). In this context, it was also found that Arabica and Robusta green coffee beans had a normal odour (Table 1), showing no deterioration from chemical or microbiological origin, as well as any contamination with foreign substances or defective beans that could have an impact in the olfactory characteristics. Thus, these results further become favourable indicators of the quality of the analysed samples (Bicho et al., 2011b).

When the colour of the high quality Arabica and Robusta green coffee beans, having optimal characteristics for the international market, was visually analysed, an uniform yellowish was detected (Table 1), suggesting a recent harvest followed by a dry processing. Moreover, one factor that positively contributes to further improve the appearance uniformity and colour of a bean is related to the minimization of the silverskin adherence to the bean by polishing during the benefit. Otherwise silverskin may confer to the seed a strong green tone, when carotenoids and chlorophylls are present in it, or red if only carotenoids prevail (Coste, 1992; Clifford, 1987). In this context, the residual silverskin of the surveyed samples had a reddish-brown colour, being almost absent in the groove of the green coffee beans, which is also an indicator of a dry primary processing. The green coffee samples had still predominantly flaky bean with round shape, according to the classification of Esteves and Oliveira (1970), further supported by Bicho et al. (2011b).

Considering the importance of nanotechnologies (Momin et al., 2013), the determination of the colour of green coffee bean, made with the illuminants $\mathrm{D}_{65}$ and $\mathrm{C}$ allowed the collection of coordinates systems chromatic CIEL*a*b* and CIEL*C*H $\mathrm{H}^{\circ}$ (Table 2), detecting significant differences between the coffee samples in all parameters except the coordinate $\mathrm{L}^{*}$. The parameters $\mathrm{a}^{*}$ and $\mathrm{b}^{*}$ (contribution of the green/red, and blue/yellow, respectively) presented positive values, pointing a greater contribution of the red and yellow components. The combined value of these two chromatic parameters justified the yellowish colour visually detected for both coffee 
beans. Although the lightness ( $\left.\mathrm{L}^{*}\right)$ was not significantly different, the opposite occurred with saturation $\left(\mathrm{C}^{*}\right)$ and tone $\left(\mathrm{H}^{\circ}\right)$. Jointly these three coordinates contribute to the colour observed in each sample. In fact, Arabica green coffee had a greenish yellow, while Robusta green coffee had a brownish yellow colour (with the coordinates $\mathrm{a}^{*}$ and $\mathrm{b}^{*}$ being significantly higher). Accordingly, the red and yellow colours prevail in this coffee. The values of coordinate $b^{*}$ were similar to those reported by Bicho (2005), for five wet processed coffees, which suggests that a* might be responsible for the colour differences found in the dry or wet processed green coffees. In fact, the wet processed coffee showed negative $a^{*}$ values, pointing to a major green contribution. Therefore, the greenish colour developed in beans by this type of processing, in contrast to the yellowish colour of dry processed green coffee beans (that has a positive $\mathrm{a}^{*}$ value). These data show that the coffee industry can use this difference in colour (green or yellow) as a quick way to identify the type of post-harvest processing of green coffee beans. In fact, these data, further supported by previous studies (Bicho, 2005), indicate that the differences in coordinate $\mathrm{a}^{*}$ are linked to the green coffee beans processing and variety. Nevertheless, it also must be pointed that the age of the grain can also be affected by the value of $a^{*}$ (Mendes et al., 2001). L*, a* and b* values of arabica sample are similar to those obtained by Nelson (2005) for an aged arabica coffee from Jamaica.

In grinded green coffee, the coordinates CIEL*a*b* and CIEL* $\mathrm{C}^{*} \mathrm{H}^{\circ}$, using illuminant $\mathrm{D}_{65}$, revealed that coordinates $\mathrm{a}^{*}, \mathrm{~b}^{*}, \mathrm{C}^{*}$ and $\mathrm{H}^{\circ}$ did not significantly differ between the two coffee types, unlike the parameter $\mathrm{L}^{*}$, but when we used illuminant $\mathrm{C}$, only $\mathrm{b}^{*}$ and $\mathrm{C}^{*}$ did not differ significantly (Table 2). These data points to the existence of a significant correlation between the coordinates $\mathrm{a}^{*}$ and $\mathrm{H}^{\circ}$ and the coordinates $\mathrm{b}^{*}$ and $\mathrm{C}^{*} . \mathrm{H}^{\circ}$ of grinded green coffee would be more influenced by the contribution of $\mathrm{a}^{*}$ (that presents a higher variation) than coordinate $b^{*}$, thus suggesting that $\mathrm{a}^{*}$ would determine the colour of green coffee. For $\mathrm{C}^{*}$ calculation the $\mathrm{b}^{*}$ coordinate assumes a higher importance than $\mathrm{a}^{*}$ due to its higher value. Thus the absence of $b^{*}$ variation would justify the absence of significant differences among $C^{*}$ values.

The predominant colour of green coffee depends on factors related with the botanical source and processing type (Coste, 1992). However, bean colour also develops during the green coffee processing, without the contribution of chlorophylls (Clifford, 1987), being mostly associated to fermentation and drying (Coste, 1992). Such colour also depends on the nature of soil and agricultural techniques applied and the duration and conditions of storage (Coste, 1992). The latter two factors do not seem to affect negatively the analysed samples since were freshly collected. After comparing the results of coordinate systems CIEL*a*b* and CIEL*C* $\mathrm{H}^{\circ}$, for parameters $\mathrm{L}^{*}, \mathrm{a}^{*}, \mathrm{~b}^{*}, \mathrm{C}^{*}$ and $\mathrm{H}^{\circ}$, using as variables both illuminants $\left(D_{65}\right.$ and $\left.C\right)$, it was found that the samples of green coffee beans (Table 2) did not show clear different values.

Table 2. Chromatic parameters of Arabica and Robusta coffee samples. Each value is the mean of 9 replicates \pm S.E.

Different letters $(r, s)$ indicate significant differences after a mean comparison by the

Tukey's test at a 95\% confidence level.

\begin{tabular}{|c|c|c|c|c|c|}
\hline & \multicolumn{5}{|c|}{ Chromatic parameters } \\
\hline & $\mathrm{L}^{*}$ & $a^{*}$ & $\mathrm{~b}^{*}$ & $\mathrm{C}^{*}$ & $\mathrm{H}^{\mathrm{o}}$ \\
\hline \multicolumn{6}{|l|}{ Entire beans } \\
\hline Arabica & $57.54 \pm 0.83^{\mathrm{r}}$ & $2.02 \pm 0.17^{\mathrm{r}}$ & $13.37 \pm 0.39^{r}$ & $13.53 \pm 0.40^{\mathrm{r}}$ & $81.47 \pm 0.63^{r}$ \\
\hline Robusta & $56.93 \pm 0.85^{\mathrm{r}}$ & $3.50 \pm 0.27^{\mathrm{s}}$ & $16.19 \pm 0.36^{\mathrm{s}}$ & $16.58 \pm 0.36^{\mathrm{s}}$ & $77.79 \pm 0.93^{\mathrm{s}}$ \\
\hline & Illuminant $\mathrm{C}$ & & & & \\
\hline Arabica & $57.19 \pm 0.70^{r}$ & $1.41 \pm 0.14^{\mathrm{r}}$ & $13.50 \pm 0.58^{r}$ & $13.57 \pm 0.58^{r}$ & $84.08 \pm 0.52^{r}$ \\
\hline Robusta & $57.27 \pm 0.88^{\mathrm{r}}$ & $3.03 \pm 0.25^{\mathrm{s}}$ & $16.22 \pm 0.21^{\mathrm{s}}$ & $16.52 \pm 0.19^{\mathrm{s}}$ & $79.40 \pm 0.92^{\mathrm{s}}$ \\
\hline Grinded beans & \multicolumn{5}{|l|}{ Illuminant $\mathrm{D}_{65}$} \\
\hline Arabica & $72.11 \pm 0.27^{r}$ & $1.06 \pm 0.04^{\mathrm{r}}$ & $15.84 \pm 0.12^{r}$ & $15.88 \pm 0.12^{\mathrm{r}}$ & $86.19 \pm 0.15^{\mathrm{r}}$ \\
\hline Robusta & $75.29 \pm 0.16^{s}$ & $0.89 \pm 0.02^{\mathrm{r}}$ & $15.83 \pm 0.13^{r}$ & $15.85 \pm 0.13^{\mathrm{r}}$ & $86.79 \pm 0.07^{\mathrm{r}}$ \\
\hline & \multicolumn{5}{|l|}{ Illuminant $\mathrm{C}$} \\
\hline Arabica & $71.69 \pm 0.07^{r}$ & $0.90 \pm 0.01^{r}$ & $15.90 \pm 0.06^{\mathrm{r}}$ & $15.93 \pm 0.06^{\mathrm{r}}$ & $86.75 \pm 0.04^{r}$ \\
\hline Robusta & $75.98 \pm 0.05^{\mathrm{s}}$ & $0.66 \pm 0.02^{\mathrm{s}}$ & $15.93 \pm 0.09^{\mathrm{r}}$ & $15.95 \pm 0.09^{\mathrm{r}}$ & $87.62 \pm 0.08^{\mathrm{s}}$ \\
\hline
\end{tabular}


However, with the illuminant $\mathrm{C}$, the coordinate $\mathrm{a}^{*}$ showed a slightly lower value and the coordinate $\mathrm{H}^{\mathrm{0}}$, was higher. In ground green coffee (Table 2) significant differences were found for parameters $\mathrm{a}^{*}$ and $\mathrm{H}^{\circ}$, whereas the opposite occurred to the other parameters $\left(\mathrm{L}^{*}, \mathrm{~b}^{*}\right.$ and $\left.\mathrm{C}^{*}\right)$. Also, in this case, using the illuminant $\mathrm{C}$, a similar trend was found to that reported for green coffee beans, occurring a significant lower value for the coordinate $\mathrm{a}^{*}$ and a higher value for the coordinate $\mathrm{H}$. Moreover, it was interesting to find that the parameters $\mathrm{L}^{*}$ and $\mathrm{H}^{\circ}$ followed similar patterns using both illuminants, $\mathrm{D}_{65}$ and $\mathrm{C}$, to a previous study on roasted coffee grains (Bicho, 2005).

\section{Conclusion}

The chromatic parameters, which allow a fast, reliable, low cost and non-destructive analysis that integrates the result of several processes, from plant production until storage, was able to partially differentiate the quality of Arabica and Robusta green coffee samples within the established range of the international market, and having good storage conditions. Yet, as coordinate a* strongly affects tone of the green coffee in the colour analysis, the illuminant type used in the measurement must be defined and/or combined. In fact, our study showed that the variation of spectral composition of incident light leads to a different colour perception.

\section{Acknowledgements}

The authors wish to thank NovaDelta company/Portugal, for supplying the green coffee samples and Professor Doctor Santos Oliveira (FCT/UNL) for his scientific suggestions.

\section{References}

ABIC. 2007. Revisão 15 - Norma de qualidade recomendável e boas práticas de fabricação de cafés torrados em grão e cafés torrados moídos [Recommended quality standard and good manufacturing practices for roasted coffee beans and roasted grind coffee]. Associação Brasileira da Indústria do Café, pp.1-20, Brasil. [in Portuguese].

Bicho, N. C. C. 2005. Qualidade e segurança alimentar no café verde e aclimatação do género Coffea em condições de stress ambiental [Food quality and safety in green coffee and acclimation of the Coffea genus in environmental stress conditions]. Faculdade de Ciências e Tecnologia, Universidade Nova de Lisboa, p. 389, Portugal. [in Portuguese].
Bicho, N. C. C., A. E. Leitão, J. C. Ramalho, N. B. Alvarenga and F. C. Lidon. 2011a. Identification of chemical clusters discriminators of the roast degree in Arabica and Robusta coffee beans. Eur. Food Res. Tech. 233:303-311.

Bicho, N. C. C., A. E. Leitão, J. C. Ramalho, N. B. Alvarenga and F. C. Lidon. 2011b. Identification of nutritional clusters descriptors of roasting intensity in beverages of Arabica and Robusta coffee beans. Int. J. Food Sci. Nut. 62(8):865-871.

Bicho, N. C. C., A. E. Leitão, J. C. Ramalho, N. B. Alvarenga and F. C. Lidon. 2012. Application of colour parameters for roasting coffee assessment. Ciência e Tecnologia dos Alimentos 32(2):1-7.

Bicho, N. C. C., J. F. S. Oliveira, A. E. Leitão, J. C. Ramalho and F. C. Lidon. 2011c. O Café Origens, Produção, Processamento e Definição de Qualidade. [Coffee - Origins, Production, Processing and Quality Definition]. Livraria Escolar Editora. P. 170, Lisboa, Portugal. [in Portuguese].

Chervin, C., P. Franz and F. Birrell, F. 1996. Calibration tile slightly influences assessment of color change in pears from green to yellow using de L,a,b space. Hort. Sci. 31:471.

Clifford, M. N. 1987. Chemical and physical aspects of green coffee products. In: M. N. Clifford and and K. C. Wilson (Eds.) pp. 305374. Coffee, Botany, Biochemistry and Production of Beans and Beverage. Croom Helm \& Methuen Inc, New York, USA.

Cortez, J. G. 2001. Proposal for a global system to improve coffee. Comments and suggestions. Document WP Quality no 3/01, 31/10/2001. International Coffee Organization 1-8.

Coste, R. 1992. Coffee: the plant and the product. MacMillan Press Ltd, London, UK.

Esteves, A. B. and J. S. Oliveira. 1970. Contribuição para o estudo das características dos cafés de Angola [Contribution to the study of Angola coffees characteristics]. Junta de Investigações do Ultramar, Estudos Ensaios e Documentos 126:1-177. [in Portuguese].

Fazuolli, L. C. 1986. Genética e melhoramento do cafeeiro [Coffee genetics and breeding]. In: Cultura do Cafeeiro-Factores que afectam a produtividade, Associação Brasileira para 
Pesquisa da Potassa e do Fosfato, p. 89-113, São Paulo, Brasil. [in Portuguese].

Florián, J. C., J. B. Valdivia, L. C. Guevara and D. C. Lianos. 2013. Antidiabetic effect of Coffea arabica, in alloxan-induced diabetic rats. Emir J. Food Agric. 25(10):772-777.

ICC. 2004. Resolução $\mathrm{n}^{\mathrm{o}}$ 420. Programa de Melhoria da Qualidade do Café Modificações [Resolution No. 420. Coffee quality improvement programme Modifications]. International Coffee Organization, pp. 1-3, London, UK. [in Portuguese].

ICO. 2009. Trade statistics. International Coffee Organization, London, UK. Available via dialog: http://www.ico.org/coffee_prices.asp. Accessed: $21^{\text {st }}$ August 2011.

Instrução Normativa $n^{\circ}$ 8. 2003. Regulamento técnico de identidade e de qualidade para a classificação do café beneficiado grão cru [Technical regulation of identity and quality for the classification of raw green coffee beans]. Ministério de Estado da Agricultura, Pecuária e Abastecimento, p. 1-12, Brasil. [in Portuguese].

ISO 10470. 2004. Defect reference chart. In: WP Board no 1005/06, Qualité: harmonisation de la résolution du Conseil International du Café numéro 420 avec la table ISO des défauts du café vert [Quality: harmonization of the International Coffee Council resolution No. 420 with the ISO green coffee defects table]. International Coffee Organization, p. 4-7, London, UK. [in French].

ISO 4072. 1982. Green coffee in bags-sampling. International Organization for Standardization, p. 1-3, Switzerland.

ISO 4149. 2005. Green coffee-Olfactory and visual examination and determination of foreign matter and defects. International Organization for Standardization, p. 1-5, Switzerland.

ISO 4150. 1991. Green coffee-size analysis-manual sieving. International Organization for Standardization, p. 1-6, Switzerland.

ISO 6673. 2003. Green coffee-Determination of loss in mass at $105{ }^{\circ} \mathrm{C}$. International Organization for Standardization, p.1-4, Switzerland.

Mcguire, R. G. 1992. Reporting of objective colour measurements. Hort. Sci. 27: 1254-1255.
Mendes, L. C., A. C. Menezes, M. Aparecida and A. P. Silva. 2001. Optimization of the roasting of robusta coffee (C. canephora Conillon) using acceptability tests and RSM. Food Qual. Pref. 12:153-162.

Momin, J. K., Jayakumar C. and Prajapati, J. B. 2013. Potential of nanotechnology in functional foods. Emir J. Food Agric. 25(1):10-19.

Nelson, G. 2005. Using colorimetry as analytical technique for quality assessment of green coffee beans. XXI Latin American Coffee Industry Symposium, San Salvador, El Salvador, 14-15 July 2005. Available at: http://www.ciboj.org/cib/certification/ENRD/ WebReadyPowerPointshowsfromENRD/Colo rimetryasAnalyticalTechnique.pps. Accessed: $16^{\text {th }}$ April 2012.

NP 1535. 1977. Café-Terminologia [CoffeeTerminology]. Repartição de Normalização da Inspecção-geral dos Produtos Agrícolas Industriais, p. 1-6, Portugal. [in Portuguese].

NP 1795. 1989. Café-Café verde. Exame olfactivo e visual [Coffee-Green coffee. Olfactory and visual examination]. Instituto Português de Qualidade, p. 1-4 Lisboa, Portugal. [in Portuguese].

NP 2285. 1991. Extractos secos de café e de sucedâneos - Determinação da massa volúmica aparente por escoamento livre [Dried extracts of coffee and coffee substitutes - Determination of apparent density through free-flowing]. Instituto Português de Qualidade, p. 1-6, Lisboa, Portugal. [in Portuguese].

Regulamento (CE) $\quad \mathrm{n}^{\mathrm{o}}$ 123/2005. 2005. Regulamento da Comissão (26/1/2005) que altera o Regulamento (CE) $\mathrm{n}^{\circ} 466 / 2001$ no que diz respeito à ocratoxina $\mathrm{A}$ [Commission Regulation (26/01/2005) that amends Regulation (EC) No 466/2001 concerning ochratoxin A]. Oficial J. Eur. Union L25:3-5. [in Portuguese].

Soedibyo, D. W., U. Ahmad, K. B. Seminar and I. D. M. Subrata. 2010. The Development of Automatic Coffee Sorting System Based on Image Processing and Artificial Neural Network. Proceedings of AFITA 2010 International Conference - The Quality Information for Competitive Agricultural Based Production System and Commerce, 
Bogor Agricultural University, p. 272275West Java-Indonesia. Available at: http://repository.ipb.ac.id/handle/123456789/4 1672. Accessed: $16^{\text {th }}$ April 2012.

WP Board $\mathrm{n}^{\mathrm{o}}$ 1005/06. 2006. Qualidade: Harmonização da Resolução número 420 do Conselho Internacional do Café com a Tabela de Referência de Defeitos do Café Verde da ISO [Quality: harmonization of the International Coffee Council Resolution $\mathrm{N}^{\circ}$ 420 with the ISO green coffee defects reference table]. International Coffee Organization, p.1-9, London, UK. [in Portuguese]. 